\title{
Service Learning: A Multidimensional Approach to Meaningful Learning Outcomes in a Practice Profession
}

\author{
Misty G. Smith, DSW \\ Assistant Professor, Department of Social Work \\ Tarleton State University
}

\begin{abstract}
A service learning project was used to encourage social work student engagement with older adults, support a community need, and meet the course objectives, one being conducting a social work assessment. Paired with an older adult resident, students applied theoretical concepts to a practice experience to meet student learning outcomes and expand comfort levels. Fourteen students participated in the convergent-mixed methods study. Assessment scales regarding bias and knowledge were administered and written reflections were recorded. Findings suggest students experienced deeper learning from applying theory and skills and had a positive shift in perspectives of older adults through the service-learning experience.
\end{abstract}

Globally, a demographic milestone is currently in progress, and adults aged 65 years or older will shift to outnumbering young children. One major challenge this demographic shift presents is the care of older adults, which will cause a complex nature of health issues to rise and make the management of care across health and social service arenas critically important (World Health Organization, 2018). Social workers focus on the holistic care of others and possess competency in navigating complex health and social service systems (Australian Association of Social Workers [AASW], 2015). Thus, social work will be one of the integral disciplines needed in the health care arena to work with the aging population.

Although the majority of social workers report that they serve older adults, a very small number identify the aging field as their primary practice area (The George Washington University Health Workforce Institute, 2017). To address this gap, social work programs have an integral responsibility to prepare students to work with older adults upon their graduation; although, working with the aging population still remains an unfavorable option for practice settings among students due to a lack of familiarity and bias of older adults (Masciadrelli, 2014).

Performing a comprehensive social work assessment is a fundamental task in social work practice (AASW, 2015). Assessment occurs in all practice settings with all populations. Mastery of social work assessment is a core competency in the 2015 Educational Policy and Accreditation Standards (EPAS) of the Council on Social Work Education (CSWE); therefore, it is embedded in the core social work curriculum (CSWE, 2015). The purpose of this study was multifocal. The first goal was to enhance undergraduate students' comfort level with older adults. The second goal was to assess undergraduate students' bias and knowledge related to aging. The third goal was to provide undergraduate students with an early opportunity to use social work skills in practice through the implementation of a service-learning project with older adults to achieve course learning outcomes of performing the bio-psycho-social-spiritual assessment. 


\section{Literature Review}

The population of older adults is projected to double by 2050 based on the number of older adults in 2012 (Ortman et al., 2014). By 2050, it is estimated that 83.7 million individuals will be aged 65 and over. The aging of the population will significantly affect the delivery of health care in the United States. The compilation of advances in medical interventions and an increase in life expectancy have shifted previously fatal diseases to lifelong conditions (Spitzer \& Davidson, 2013). Experiencing multiple medical conditions simultaneously becomes more common as individuals age (World Health Organization, 2018). Although much of the focus resounds on the management of medical care in late adulthood, addressing social factors are as integrally important (Kotwal \& Perissinotto, 2019). Fundamental social roles change in older adulthood; changes involving retirement, death of family/friends, and widowhood can place older adults at risk for developing loneliness and isolation. For older adults over 60 years of age living in communities within the United States, the rate of loneliness was reported to be as high as $43 \%$. Studies have revealed an association between loneliness and isolation with worsened chronic healthcare conditions (Kotwal \& Perissinotto, 2019). Therefore, physical as well as psychosocial needs increase in older adulthood.

\section{Student Interest in the Aging Population}

Due to a youth-oriented culture and devaluation of older adults, students in social work select working with the aging population as their least favored choice. Social work with the aging population is not viewed as exciting or interesting, which influences the students' perceptions (Masciadrelli, 2014). Students' negative attitudes toward older adults were associated with a lack of exposure to this population (Wang \& Chonody, 2013). Research has demonstrated that direct interaction between students and older adults can increase their interest in this population and decrease aging biases (Borrero, 2015; Masciadrelli, 2014). One finding consistent in the literature indicates that experience with the older adult population is one of the most significant predictors of future work in the field of aging (Wang \& Chonody, 2013). Another key finding in the literature suggests students did not feel adequately prepared to work with the older adult population; a lack of adequate course work and training existed (Wang \& Chonody, 2013). The conclusion can be drawn that practical experience is essential for increased self-efficacy especially with regard to populations and topics students prefer to evade.

\section{Service-Learning Pedagogy and Social Work}

Based on the CSWE 2015 Educational and Policy Accreditation Standards, the expectation for generalist social work students is to not only demonstrate knowledge of the social work competencies but also to demonstrate their ability to perform the competencies upon degree completion (CSWE, 2015). Therefore, the earlier undergraduate students are provided hands-on opportunities within the curriculum 
to practice their skills and professional behaviors before entry into the social work capstone, the higher the likelihood that they will be able to demonstrate competence upon graduation. Because service learning is a type of high impact practices (HIP), it is promoted in higher education due to its impact on educational outcomes and personal development (Kinzie, 2012). Based on the literature, through the use of service-learning pedagogy, two primary purposes can be attained, 1) students have the opportunity to apply learning to real community issues and reflect on these service experiences in the classroom setting "through the interplay between theory and practice" and 2) students provide deliberate service to address a community problem that is of benefit to the community itself (Bringle et al., 2004, p. 4; Kuh, 2008).

Facing the reality of living in a skilled nursing facility is a significant transition for older adults. This transition can create isolation and loneliness from social interaction and support (Adams, 2013). Individuals can experience social loneliness from lack of companionship, loss, or transition. In review of studies conducted with older adults, women over age 80 and those with lower incomes were more likely to experience loneliness, which can be a risk factor for depression (Adams, 2013). Skilled nursing facility residents are at a higher risk for decreased social engagement, which has an impact on medical, psychological, and social well-being. As a result, increasing social engagement is a vital focus of care (Bliss et al., 2017). Within skilled nursing facilities, friendly visitor programs have been initiated as a strategy to ease loneliness in older adults (Adams, 2013).

Participants in this service-learning project had the opportunity to provide support to the skilled nursing facility. Due to the nursing facility's location in a rural community, many of the residents are disconnected geographically from family and friends, resulting in little to no interaction except for facility staff. Through this pedagogy, participants provided a service to the older adult residents by offering interaction and ongoing visits from a new individual from the community, in an effort to prevent loneliness. In addition, students benefited by applying social work engagement and assessment skills to assist in addressing and understanding an actual community need within the older adult population. The facility employs one social worker for 100 residents, which causes the social worker difficulty in being able to meaningfully communicate with every resident daily. Thus, through students using their assessment knowledge and skills, they were able to share information with the social worker to better help address resident needs. The students were able to identify areas of need that the staff was unable to observe in their brief interactions. This service aided in the ongoing continuum of care of residents. Using service learning with students of helping disciplines and older adults has resulted in successful outcomes of changes in perceptions and attitudes toward this population (Augustin \& Freshman, 2016; Kanenberg et al., 2014).

\section{Scholarship of Teaching and Learning (SoTL)}

The practice of our academic disciplines is constantly evolving to maintain relevance in a changing societal context. Therefore, as academic educators preparing students for these diverse fields, continuing professional development becomes vital and the scholarship of teaching and learning (SoTL) serves as a systematic method 
toward maintaining this responsibility. Employing SoTL can add value to the overall university's academic mission, further the knowledge of our academic fields, and promote engagement within the context of our university communities (Yusoff et al., 2013). It provides a "framework for engaging in scholarship that informs our teaching and energizes our service" by integrating the holistic roles of educators, including scholarship, research, and service (Grise-Owens et al., 2016, p.10). For social work educators, it also promotes our ethical responsibility of competence in practice (National Association of Social Workers, 2018). As indicated in previous literature, the most effective way for adults to learn is through their active involvement in the process of learning; thus, as educators, Elton (2009) poses that this would be best accomplished by educators using reflection of their own teaching practice to find continuous solutions. According to Bowen's (2010) analysis of peer-reviewed journal articles, which focused on service learning in the scholarship of teaching and learning among a variety of disciplines (hard sciences, human services, humanities, and education), four themes emerged: real-world application, collaboration and interaction, meaning making through reflection, and enhancement of the course content. These emerging themes reflected the nature, experiences, and outcomes of service-learning-based SoTL projects. Each of these themes was used in this service-learning project with older adults. Student participants addressed an actual community need, collaborated and interacted with older adults, skilled nursing facility staff, and faculty, used ongoing reflection to deepen their learning, and, ultimately, improved the content of the course.

\section{Purpose}

The study's purpose was three-fold. The first goal, with undergraduate students, was to increase their comfort level with the older adult population. The second goal was to discern any biases related to older adults among undergraduate students and their level of knowledge related to aging. The final goal aimed to attain the course learning objective of completing a bio-psycho-social-spiritual assessment, by providing opportunities for undergraduate students to apply their social work skills in an actual practice setting through a service-learning project with older adults.

RQ1: What biases toward older adults changed from the beginning to the end of the course?

RQ2: What knowledge on aging changed from the beginning to the end of the course?

RQ3: Through the service-learning experience in this course, how were knowledge and skills of social work applied to achieve learning outcomes and how was the comfort level with older adults changed?

\section{Methods}

The Council on Social Work Education (CSWE) adopted a competency-based educational framework in 2008. As an accredited program of CSWE, this approach requires social work faculty to assess students' abilities to demonstrate these competencies within their curriculum (CSWE, 2015). Within a core undergraduate course of social work, Human Behavior in the Social Environment (HBSE), students are 
required to demonstrate the generalist competency of assessment with individuals of any age as they learn the human developmental lifespan. Assessments are an essential practice activity in social work and require the collection of past and present biological, psychological, social, and spiritual information using an intergenerational lens. This project was a catalyst for simulating the course content by establishing a relationship and understanding a different generational perspective (Bostrom \& Schmidt-Hertha, 2017).

\section{Procedures}

In the Human Behavior in the Social Environment (HBSE) undergraduate social work course, students have been required to complete a bio-psycho-socialspiritual assessment assignment to demonstrate mastery of the social work competency of assessment. Historically, students viewed a video and were instructed to select a character in the video to represent their client for the assessment assignment. To implement a new teaching strategy, service-learning pedagogy was embedded to complete an existing bio-psycho-social-spiritual assessment assignment and move away from using a video to achieve the student learning outcome; however, the grading rubric remained the same. Students were paired with an older adult in a skilled nursing facility in the local community to conduct their bio-psycho-social-spiritual assessment assignment.

The facility was located in the local community off the campus site and certified as a skilled nursing facility (SNF) by Medicare. Skilled nursing facilities provide skilled nursing or skilled therapy to help treat and manage patients' health care needs (United States Centers for Medicare and Medicaid Services, 2021). The social worker employed by the facility determined which residents were able physically and cognitively to interact with the students for this purpose. The facility social worker discussed the assignment with the residents to garner their permission for students to be paired. The ages of the residents ranged from 60 to 85 . The majority of the residents were female and long-term care residents. The majority of the older adults had multiple chronic health conditions consisting of diabetes, chronic obstructive pulmonary disease, depression, hypertension, heart disease, and cerebrovascular accidents.

After obtaining a letter of support from the local skilled nursing facility, approval was received from the university's Institutional Review Board. A convergent mixed-methods design was used for this study; both quantitative and qualitative data were collected to obtain different forms of information for confirmation (Creswell, 2014). The aim was not only to assess participants' biases and knowledge of older adults through the collection of quantitative data. It was also to better understand the possible underlying reasons for these biases, how the participants applied social work knowledge and skills to meet the course learning outcomes, and whether participants enhanced their comfort level with older adults through the service-learning project from the qualitative data. Thus, a convergent mixed-methods design was selected. At the start of the academic semester, the course syllabus was reviewed and each assignment was explained in detail. Students were informed about being paired with an older adult in a skilled nursing facility to complete the assessment assignment. At the conclusion of the first class day, students were informed about the research project 
and were provided the opportunity to voluntarily participate. No incentives were provided for participation. Students who did not want to participate in the study were not required to complete the two pre- and post-assessment scales, but they were still required to participate in the service-learning project as it was being introduced as a new pedagogy for this course, in spite of the study. Students were made aware that if they had any external barriers (i.e. transportation issues, employment conflicts) participating in the service-learning project, an alternative assignment could be offered; however, visits to the facility occurred during the assigned meeting time for the course. Students choosing to participate in the research study signed an informed consent form after the first class session was dismissed; the students choosing to participate in the study were asked to complete two pre-/post-assessment scales outside of the regularly assigned course assignments. A random identification number was provided to each student to use when completing the pre-/post-assessment scales online in the Qualtrics system, as the participants' signed consent forms were not connected to the pre-/post- data. Students participating in the research project completed the pre-assessment scales during the first week of the 16-week course and the post-assessment scales in the final week of the course. The skilled nursing facility provided a brief orientation with the students prior to interaction with the residents.

\section{Participants}

Although all of the students enrolled for the course were required to complete the bio-psycho-social-spiritual assessment and corresponding reflection assignments with an older adult to meet the course expectations, only the data from the students who consented and chose to voluntarily participate in the research study were included. Of the 20 undergraduate students enrolled for the course, 17 students voluntarily chose to participate in the research project. Of the 17 student participants, 10 were Caucasian females, six were Hispanic females, and one was an African American female. The median age was 21.65 (range 20-28). Fifteen students were junior social work majors, one student was a junior child and family studies major, and one student was a senior psychology major. Of the 17 students who consented to participate in the research study, only 14 students completed both the pre- and postassessment scales but all 17 students completed the reflection questions.

\section{Materials \\ Pre/Post Scales}

Kogan (1961) developed the Attitudes toward Old People Scale, which was used to assess the students' personal attitudes and outlook toward the older adult population. This scale was used at the onset of the course and at the conclusion of the course. The scale items were listed in pairs, a negatively worded form and a positively worded form of the 17 paired statements. Each statement could be answered using six response categories on a Likert scale from strongly agree to strongly disagree. The Attitudes toward Old People Scale's Spearman-Brown reliability coefficients range from 0.66 to 0.85 (Kogan, 1961). 
Students also completed the Facts on Aging Quiz, developed by Palmore (1977) and revised by Breytspraak and Badura (2015), to assess students' knowledge level on aging in older adulthood at the beginning of the course and at the conclusion of the course and service-learning experience. Palmore's (1977) original Facts on Aging Quiz included 25 items; Breytspraak and Badura (2015) added an additional 25 items to address more contemporary issues garnering attention in the aging field since the quiz was originally developed. Palmore's (1977) original measure had no reported reliability measures; however, discriminate validity of the instrument was documented. The quiz completed by participants was a 50-item, true/false questionnaire used to measure aging knowledge or bias (Breytspraak \& Badura, 2015). According to Davis et al. (2019), the revised Facts on Aging Quiz developed in 2015 reached satisfactory reliability levels in three of four age groups (18-34, 35-49, and 50$64)$, but remained inadequate among 65 and older. The participants completing this quiz were between the ages of 20 to 28 .

\section{Student Reflections}

At the conclusion of each monthly visit with each student's assigned resident at the senior care facility, students reflected in writing on their experiences. The reflection prompts were provided by the instructor to assess students' level of understanding of the human behavior course content, integration of the assigned CSWE competencies in the practice setting, and professional development. Throughout the semester, students responded to prompts such as "What did you learn about aging and older adults from this experience?", "What are you seeing in your interactions or experience that is connected with the content in this course?", and "What can you learn from this experience to promote personal and professional growth?". An evaluation of the service-learning project was also garnered through reviewing the student reflections. Using Stringer and Dwyer's (2005) data analysis process, the author read and reread the student reflections that were typed by the students in order to gain an overall understanding of the data. Then units of meaning (codes) were identified. NVivo qualitative software was used to organize the data. After units of meaning were identified, categories were designated. Outcomes were based on the themes that emerged from all data collection methods (pre- post-scales and reflections), allowing for triangulation of the data. In addition, peer debriefing was used; a professional colleague provided a peer review of the study. Participant quotations were selected to reflect the emerging themes; accuracy of the quotations were verified by the original reflections submitted by the participants.

\section{Kogan's Attitudes toward Old People Scale}

\section{Results}

A paired-samples t-test was conducted to compare social work students' attitudes toward older adults prior to the service-learning engagement project and following the service-learning engagement project. The pre- and post-test consisted of an attitude scale of 17 paired questions for a total of 34 questions. As displayed in Table 1 , the results suggest that students shifted their attitudes significantly on seven scale 
items. These items were related to attitudes surrounding older adults' communication patterns, mood, ability to adjust, work habits, and living environments. The scale items were presented in question pairs, one question representing the negatively worded form of the question and the other question representing the positively worded form of the question. Based on the negatively framed questions, students significantly changed their attitudes from disagreement to strong disagreement. Based on the positively framed questions, students shifted their attitudes from slight disagreement to slight agreement or from agreement to strong agreement.

\section{Table 1}

Kogan's Attitudes Toward Old People Scale Items with Significant Attitude Shifts Pre/Post

\begin{tabular}{|c|c|c|c|c|c|c|c|}
\hline \multirow[t]{2}{*}{ Kogan's Scale Item } & \multicolumn{2}{|c|}{ Pre-test } & \multicolumn{2}{|c|}{ Post-test } & \multirow[t]{2}{*}{$\mathrm{t}$} & \multirow[t]{2}{*}{$\mathrm{p}$} & \multirow[t]{2}{*}{ Cohen's d } \\
\hline & $\mathrm{M}$ & SD & $\mathrm{M}$ & SD & & & \\
\hline $\begin{array}{l}\text { Most old people are } \\
\text { capable of new } \\
\text { adjustments when the } \\
\text { situation demands it }\end{array}$ & 3.85 & 0.94 & 4.42 & 0.64 & -2.280 & $* 0.040$ & -0.716 \\
\hline $\begin{array}{l}\text { Most old people would } \\
\text { prefer to continue } \\
\text { working just as long as } \\
\text { they possibly can rather } \\
\text { than be dependent on } \\
\text { anybody }\end{array}$ & 5.00 & 0.78 & 5.50 & 0.51 & -2.463 & *0.028 & -0.767 \\
\hline $\begin{array}{l}\text { Most old people tend to } \\
\text { keep to themselves and } \\
\text { give advice only when } \\
\text { asked }\end{array}$ & 3.00 & 1.10 & 3.64 & 1.15 & -2.385 & *0.032 & -0.568 \\
\hline $\begin{array}{l}\text { In order to maintain a } \\
\text { nice residential } \\
\text { neighborhood, it would } \\
\text { be best if too many old } \\
\text { people did not live in it }\end{array}$ & 2.14 & 1.23 & 1.57 & 0.64 & 2.280 & $* 0.040$ & 0.608 \\
\hline $\begin{array}{l}\text { Most old people are } \\
\text { irritable, grouchy, and } \\
\text { unpleasant }\end{array}$ & 2.42 & 0.93 & 1.92 & 0.61 & 2.463 & $* 0.028$ & 0.643 \\
\hline $\begin{array}{l}\text { Most old people are } \\
\text { constantly complaining } \\
\text { about the behavior of } \\
\text { the younger generation }\end{array}$ & 3.64 & 1.21 & 2.71 & 0.99 & 2.329 & *0.036 & 0.840 \\
\hline $\begin{array}{l}\text { One seldom hears old } \\
\text { people complaining } \\
\text { about the behavior of } \\
\text { the younger generation }\end{array}$ & 2.42 & 0.75 & 3.50 & 1.45 & -3.018 & $* 0.009$ & -0.969 \\
\hline
\end{tabular}

Note. ${ }^{*} \mathrm{p} \leq .05$ 
Pre- and post-test results of the Facts on Aging Quiz revealed significant changes on two of the 50 items on the questionnaire following the service-learning project. Results indicated a significant increase in students' knowledge from the preto post-test scores for the questionnaire item that older adults are at risk for HIV/AIDS (Pre-test: $\mathrm{M}=1.50, \mathrm{SD}=0.52$ ) (Post-test: $\mathrm{M}=1.21$, $\mathrm{SD}=0.43$ ). In addition, results indicated a significant increase in students' knowledge from the pre- to post-test scores for the questionnaire item that most old people are set in their ways and unable to change (Pre-test: $\mathrm{M}=1.57, \mathrm{SD}=0.51$ ) (Post-test: $\mathrm{M}=1.93, \mathrm{SD}=0.27$ ).

\section{Student Reflection Themes}

As reflection is an essential component of service learning, reflection questions were assigned by the instructor to coincide with students' experiences. The goal of the reflection prompts were to assess students' level of understanding of human behavior content, integrate the related CSWE assessment competencies in the practice setting, identify perceptions, and evaluate professional development.

\section{Theme 1 - Practice Experience}

Practice experience emerged as a theme in thirteen student reflections. Students valued being provided a hands-on learning opportunity to practice their micro social work skills. This experience afforded students the chance to employ the skills and knowledge that they had learned in the classroom setting. Students highlighted the use of confidentiality in an actual client situation, conducting a micro client assessment, identifying non-verbal cues, attending, and maintaining their professional role. Examples of statements that illustrated the value of the practice experience theme follow:

This assignment made me more aware of my abilities as a future social worker to work with the elderly population on a micro level, keep information confidential, complete an assessment over a client's lifespan while integrating scholarly references and theories used in the social work profession.

It has made known to me that body language is a key factor on how the client is feeling, even if they are not speaking verbally to me, and it is important to be able to assess non-verbal behavior, just as well as verbal.

I will have clients that I will get along with and want to be their friend, but as a social worker if I was only there to be in the friendship role I would not be helping the client. I need to make sure I am always practicing social work skills and the social work code of ethics. Each client and situation is going to be different, I have to make sure I am always adapting to help my client in the best way possible. 


\section{Theme 2 - Use of Social Work Skills}

The use of social work skills emerged as a theme in thirteen student reflections. Students were able to recognize, identify, and use the social work skills in a practice setting that were previously introduced in the program's curriculum content. Students specifically identified skills such as active listening, building rapport, applying critical thinking, conveying empathy, using non-verbal skills, and using questioning. Based on the reflections, the most common skill used was practicing different types of questioning. Students reported the need to modify and shift the types of questions being asked while in the midst of the interaction with the client. Examples of statements that illustrated the theme of the use of social work skills follow:

I had to use the skills of asking specific questions. When I would ask my patient broad questions, she did not give deep responses, so I had to ask multiple, specific, questions.

I had to plan ahead, of how I was going to ask questions as well as knowing other ways to ask the same question because sometimes the residents would not understand.

Empathy was portrayed when she talked about difficult topics, because I wanted her to know that I understood and could share what she was feeling.

\section{Theme 3-Student Observations}

A variety of observations, which were revealed through this experience, emerged as a theme in thirteen student reflections. The two most common observations were related to professional awareness and the exposure of the experience. Students shifted their ideas and beliefs and assumed recognition of professional awareness through their engagement with the older adult population in this experience. Examples of statements that illustrated the theme of student observations follow:

I believe personally and professionally this experience will help me to be perfectly comfortable with the elderly population.

I did learn older adults are open and willing to discuss their life story to a stranger. They are also joyful to visit with a younger person. My client invited me to visit her any time after the assignment process ended.

I quickly realized not to make assumptions about clients, as you never know what they will be like.

I have learned it is important to include the client in the decision-making process and make them feel important and that they have a voice.

I learned that aging and older adults are in need of services just like any other population, and I should not feel afraid to work with this population. 
Application of social work content to this experience was a theme that emerged in fourteen reflections. Students were able to make specific connections with content from the HBSE course as well as other courses in the social work program's curriculum. Examples of the reflection statements noted by students for this theme are as follows:

I learned that the human development over the lifespan is far more than what a textbook can define for you.

Through this assignment, I was able to learn about human development across the lifespan by gathering information from my partner's life and her personal experiences. By doing so, I was able to connect her experiences to specific developmental stages.

I learned that with human development in this assignment that there is never a point where someone is not changing whether that be physically, mentally, or emotionally. Human development is crucial throughout the lifespan and it never becomes unimportant. I learned that older adults and aging is different for everyone.

I learned about resilience, increasing age, health problems, and many other things that are beneficial to learning. I think it was helpful to learn about someone in a lifespan we may not be able to listen to and learn about.

We have talked about death and end of life in the classroom and a lot of the time my partner talked about death and how she has had so much of that in her life.

\section{Theme 5-Student Strengths}

A theme that emerged in fourteen reflections was that student's self-assessed strengths about their experience interacting with their older adult partner for this assignment. Students recognized a variety of different strengths in their skill use such as recalling information, expressing empathy, listening, adapting, being open-minded, and building rapport. Examples of the reflection statements shared by students to illustrate this theme are as follows:

My strength during the assignment was that I was able to retain a lot of the information.

A strength of the interviewer was the ability to connect with the client quickly so that the client felt comfortable to share her life stories and life challenges with the interviewer.

I adapted to meet the client's needs. I had to change the speed and pitch of my voice. This way, the client could understand what I said. 


\section{Theme 6-Student Growth Areas}

The students identified areas for growth that emerged as a theme in thirteen student reflections from this experience. Students shared the growth areas of transitioning to different topics, decreasing nervousness, improving documentation, and remaining objective. Examples of the statements shared by students to demonstrate this theme are as follows:

I learned I will need to improve my focus when holding conversations with clients as a practitioner. There were times I could not recall information the client had shared with me. It will be important for me to remember information shared and topics discussed in sessions with my clients as a social worker.

I found that I need to work on becoming more comfortable when speaking with clients. I have a bad habit of freezing up when speaking with a client, especially one who is older than I am. I do not feel that I am competent yet and rather than working on it and practicing, I let it consume me.

I also need to practice boundary setting, I had difficulties sometimes mixing personal and professional boundaries.

I felt it was a struggle for me to transition topics or had trouble responding to difficult answers the client would disclose.

\section{Theme 7-Overall Takeaway}

Ten students reflected on their overall takeaway from this experience. Students shared feedback on how this experience provided them with deeper meaning with regard to the older adult population, their perspectives on life, information on human development, hands-on experience in social work, and personal confidence. Examples of the statements reflecting this theme are as follows:

This assignment was a learning experience and helped myself broaden my options with populations to work with in the future. Personally having a bad experience with the older population within my family concerning the elder population and care centers, but the opportunity to work with the older population was a positive experience and changed my opinion on this population.

I learned human development never stops, regardless of age. My patient is 99 years old and is still developing. Although she is getting closer to death, she is still constantly changing and growing. I learned aging and older adults still enjoy playing games and making jokes. They do not sit around all day doing nothing, they are very active considering their age. 
From this experience I learned that I have the ability to do far more than I think I am capable of. I stretched myself further than my comfort zone and I learned so much.

I learned that I am a little stuck in my thoughts when it comes to the way that people should welcome you into their lives. I also learned that I truly need to improve on my skills of speaking to people about all aspects of their life. I was very surprised how similar the beginning of life is to the end of life.

\section{Converged Data}

Through convergence of the quantitative and qualitative data, outcomes indicated participants shifted their bias in specific areas toward older adults that were noted on the scale. The data also provided further meaning for the underlying explanations for these biases toward this population, as many students had not had previous experience interacting with older adults. In addition, the qualitative data revealed other biases toward older adults that were not captured on the pre- and postassessment scale. As a result, this information provided a more holistic participant perspective from the beginning of the course until the end. Although quantitatively it Participants were able to make connections between theory and practice through the realworld application of a practicebased simulation. may have appeared that participants' knowledge of older adults did not change extensively from course beginning to end, the qualitative data provided a comprehensive viewpoint about the depth of knowledge gained. In particular, participants experienced the human behavior course content demonstrated through the service-learning project and the direct interaction with older adults. Overall, the data indicated that students had the opportunity to build their confidence levels in their application of social work knowledge and skills with the older adults they were paired with. This experience enhanced their comfort levels and decreased the biases they had with interacting with this specific population. Participants were able to make connections between theory and practice through the real-world application of a practice-based simulation. Students were faced with the true intricacies of meeting the client where they are and navigating ongoing communication with regard to interpreting body language, using clarification, rewording questions, using active listening, setting boundaries, and practicing recall for documentation purposes. The aggregate of the quantitative and qualitative data revealed a more accurate representation of the true learning outcomes that students mastered.

\section{Discussion}

Based on the information collected from the social work students in the HBSE course, the service-learning project provided a genuine experience for students to overcome discomfort with older adults and build confidence in their ability to perform social work skills necessary to complete the assessment course competency. Although students' results on only two of the items on the Facts on Aging knowledge assessment 
questionnaire significantly changed, it appears that the service-learning experience increased students' comfort levels, deepened their application of assessment, and changed biases and considerations for working with older adults. Younger students, like the sample of students for the study, often do not always have a personal experience of interacting with older adults. This finding is consistent with previous research that positive interactions with older adults can improve their attitudes toward this population (Hash et al., 2017).

Assessment is a universal skill that is necessary in all settings of social work practice (CSWE, 2015). Through this service-learning experience, students encountered the true reality of a practice situation where the information needed from a client was not automatically provided to the practitioner. In previous courses, this assessment assignment was based on a movie character using only the information provided in the movie. However, this service-learning project provided students with an in vivo learning experience to encounter the true ebbs and flows of performing an assessment. Students had to apply the social work skills they had previously learned in other classes in order to retrieve the information necessary to successfully complete the course objectives. Student outcomes on the grading rubric for the assessment assignment remained consistent to the previous semesters' outcomes when students used a video for their assignment. The difference from using the service-learning experience as opposed to the video came from the deepening of students' application of social work skills. These skills included: building rapport, implementing active listening, using appropriate questioning, recalling information shared, and documenting the assessment with an actual person. This advanced their educational learning to a higher level than classroom instruction could provide. In addition, selfreflective practice was used in real-time in order to modify, adapt, and learn new ways to engage with their resident partners. Students demonstrated the ability to overcome personal discomfort both with the population of older adults as well as with the implementation of social work skills to perform an assessment. This had previously only been learned in a classroom setting using a textbook. Overcoming both areas of discomfort elevated students' confidence in their own abilities as well as altered preexisting perceptions, beliefs, and myths about older adults and the actual practice of social work.

\section{Limitations and Challenges}

There were limitations present for this study. One limitation was that this study was carried out in only one undergraduate social work course in the curriculum. This impacted the sample size of the study and its ability to be generalized. Although 17 students consented to voluntarily participate in the study, only 14 students followed through with completion of both the pre- and post- assessment scales. Fourteen students is a small sample size for quantitative data collection; however, it is a reasonable number for a qualitative data sample. Another limitation was that although the sample was varied in some demographic characteristics, it was not in others, such as gender and age. In addition, the majority of the students were social work majors, and all students participating were exclusively seeking an undergraduate degree in a helping profession. Limitations with regard to validity involved the absence of testing 
with a control group. Threats of history and maturation were also present as 16 weeks transpired between completion of the pre-test and post-test assessment scales. External events, experiences, or individual maturation could have been an attributor to the results.

The service-learning project also presented challenges to consider with regard to implementation. Although the majority of the nursing facility residents were longterm care residents, two residents paired with students were transferred from the facility mid-semester and one died. Therefore, this abrupt change for the students could have impacted their perspectives in the reflections. Another consideration of implementing a similar service-learning project is the semester's season. This servicelearning project was performed during a spring academic semester; however, considerations for the risk of health exposure is important as older adults are a vulnerable population to recovery from illness. When students were ill on a scheduled day to meet their resident, they were asked to reschedule rather than expose the resident to potential illness. Although these issues presented unique challenges for consideration, they also provided a rich integration of course content to process in class about the aging population.

\section{Implications}

Social work is a practice-oriented profession; therefore, faculty assume a major role in preparing social work students to successfully demonstrate the competencies of the profession upon their transition into practice. To address the issues that the aging demographic will present, an array of professionals in the health care arena will be needed. By 2028, health care occupations are estimated to increase 14 percent, adding 1.9 million new jobs (United States Bureau of Labor Statistics, 2019). Therefore, the implications from this study are broader than the discipline of social work alone. All students pursuing healthcare related fields need to be prepared for working with older adults and performing discipline-specific evaluations and assessments of this population. Being able to formulate a multi-dimensional assessment is a key tenant of social work practice. In order to perform this competency, students must engage in direct communication and develop rapport with individuals. Increasing opportunities to validate students' comfort, confidence, and competence continues to be necessary for effective preparation, especially with an expanding older adult population. Unlike previous studies, this service-learning project was multifocal. Not only did it aid in increasing students' comfort levels and shifting biases, but it also incorporated students' hands-on application of deepening their assessment knowledge and skills with older adults This experience increased their confidence and competence with this population in practice, which can be transferred to other populations as well. Students also realized the value of service to a population served by the profession of social work and the value of a communicative team to the ongoing care of others.

Engagement is necessary in helping professions, and students need opportunities to practice these skills in a learning environment. Having had volunteer experiences with the older adult population has shown to be a stronger indicator of interest in working with older adults than paid experiences (Wang et al., 2013). Previous research has demonstrated that students in social work as well as other healthcare fields have discomfort and unfamiliarity in engaging with older adults. In 
the future, creative ways to implement universal practice skills should be cultivated by faculty as students express discomfort and avoidance from working with certain populations. Hands-on, service, and experiential learning opportunities can be delivered to meet various learning styles (Maschi et al., 2012). These experiences can be implemented across any discipline to achieve the student learning outcomes while simultaneously building students' confidence in applying this knowledge in their future career. Difficult course concepts or specific populations that students struggle to comprehend are prime areas to target to enrich the integration and mastery of student learning outcomes through this type of endeavor. By implementing service learning, the learning gained was not just read or heard within a classroom. The learning was experienced and practiced with the support of a faculty member for discussion and guidance, which provided increased confidence and repetitive learning to secure mastery. Older adults will interface with numerous professions. For example, grandparents are raising grandchildren and will need to interface with educators as well as learn new technology in order to assist their grandchildren with meeting these responsibilities. Although this project focused on older adults, other disciplines could integrate these techniques that have the potential to achieve student learning outcomes through service learning. Engineering students may be able to partner with the community to identify solutions to flooding in particular areas of the town. Mathematic students could partner with the transportation department or parking office at the university to analyze the most efficient traffic patterns, mutually employing a service and also applying learning concepts.

Future research could explore participants' attitudes and biases toward older adults on scale items that, although not statistically significant, the outcomes were close to being significant. These biases included older adults prying and providing unsolicited advice, taking care of their homes, talking about their past and it boring others, and their ability to be understood. These areas could be explored further with future research, especially among a larger sample size. Although older adults are isolated in skilled nursing facilities and need socialization, additional research on the impact of student service-learning projects on the client population is needed. Results from the study indicated, from students' reflections, that the service-learning engagement with older adults was effective in helping students to understand the social work process of assessment and achieve the course learning outcomes on the developmental stage of older adulthood. Future research should also evaluate the effect of the project from the client and community partner perspective.

\section{References}

Adams, K. B. (2013). Late adulthood. In J. B. Ashford \& C. W. Lecroy (Eds.). Human behavior in the social environment (pp. 595-655). Brooks/Cole Cengage Learning.

Augustin, F., \& Freshman, B. (2016). The effects of service-learning on college students' attitudes toward older adults. Gerontology and Geriatrics Education, 37(2), 123144. https://doi.org/10.1080/02701960.2015.1079705

Australian Association of Social Workers. (2015). Scope of social work practice psychosocial assessments. Australian Association of Social Workers. https://www.aasw.asn.au/document/item/8312 
Bliss, D., Harms, S., Eberly, L. E., Savik, K., Gurvich, O., Mueller, C., Wyman, J. F., \& Virnig, B. (2017). Social engagement after nursing home admission: Racial and ethnic disparities and risk factors. Journal of Applied Gerontology, 36(11), 13061326. https://doi.org/10.1177/0733464815617285

Borrero, L. (2015). Intergenerational service learning: Bringing together undergraduate students and older adult learner to engage in collaborative research. Journal of Intergenerational Relationships, 13(2), 188-192.

https://doi.org/10.1080/15350770.2015.1025679

Bostrom, A. K., \& Schmidt-Hertha, B. (2017). Intergenerational relationships and lifelong learning. Journal of Intergenerational Relationships, 15(1), 1-3. https://doi.org/10.1080/15350770.2017.1260408

Bowen, G. (2010). Service learning in the scholarship of teaching and learning: Effective practices. International Journal for the Scholarship of Teaching and Learning, 4(2), 1-15. https://doi.org/10.20429/ijsotl.2010.040218

Breytspraak, L., \& Badura, L. (2015). Facts on Aging Quiz. http://info.umkc.edu/aging/quiz/

Bringle, R., Phillips, M., \& Hudson, M. (2004). The measure of service learning: Research scales to assess student experiences. American Psychological Association.

Council on Social Work Education. (2015). 2015 educational policy and accreditation standards for baccalaureate and master's social work programs. Council on Social Work Education.

https://www.cswe.org/Accreditation/Standards-and-Policies/2015-EPAS

Creswell, J. W. (2014). Research design: Qualitative, quantitative and mixed methods approaches ( $4^{\text {th }}$ ed.). Sage Publications, Inc.

Davis, J., Breytspraak, L., Marszalek, J., \& McDowd, J. (2019). Disentangling knowledge and bias: Combating ageism with the revised Facts on Aging Quiz. Innovation in Aging, 3(S1), 455. https://doi.org/10.1093/geroni/igz038.1703

Elton, L. (2009). Continuing professional development in higher education: The role of the scholarship of teaching and learning. International Journal for the Scholarship of Teaching and Learning, 3(1), 1-10. https://doi.org/10.1177/1474022209339955

The George Washington University Health Workforce Institute. (2017). Profile of the social work workforce. The George Washington University Health Workforce Institute.

Grise-Owens, E., Owens, L. W., \& Miller, J. J. (2016). Conceptualizing the scholarship of teaching and learning for social work education. Journal of Social Work Education, 52(1), 6-17. https://doi.org/10.1080/10437797.2016.1112628

Hash, K. M., Poole, J., Floyd, M., Moore, C. D., Rogers, A. T., \& Tower, L. E. (2017). Innovative experiential learning activities in aging: The experiences of four BEL projects. Journal of Teaching in Social Work, 37(2), 156-170.

https://doi.org/10.1080/08841233.2017.1300207

Kanenberg, H., Mapp, S., Dudley, R., \& McFarland, M. (2014). Students' perceptions of older adults: Effects of a service-learning experience. Journal of Baccalaureate Social Work, 19, 59-72. https://doi.org/10.5555/basw.19.1.64370943687111r0

Kinzie, J. (2012). High-impact practices: Promoting participation for all students. Diversity $\mathcal{E}$ Democracy, 15(3). https://www.aacu.org/publications- 
research/periodicals/high-impact-practices-promoting-participation-allstudents

Kogan, N. (1961). Attitudes toward old people: The development of a scale and an examination of correlates. The Journal of Abnormal and Social Psychology, 62(1), 44-54. https://doi.org/10.1037/h0048053

Kotwal, A., \& Perissinotto, C. (2019, May 21). Zeroing in on isolation and lonelinessBoosting social capital. Aging Today. https://www.asaging.org

Kuh, G. (2008). High-impact educational practices: What they are, who has access to them, and why they matter. Association of American Colleges and Universities.

Maschi, T., MacMillan, T., Pardasani, M., Lee, J. S., \& Moreno, C. (2012). Moving stories: Evaluation of a BSW oral history project with older adults with diverse immigration histories. Educational Gerontology, 38(4), 228-242. https://doi.org/10.1080/03601277.2010.544570

Masciadrelli, B. P. (2014). I learned that the aging population isn't that much different from me: The final outcomes of a gero-ed BEL project. Journal of Gerontological Social Work, 57(1), 34-36. https://doi.org/10.1080/01634372.2013.854855

National Association of Social Workers. (2018). The code of ethics. https://www.socialworkers.org/About/Ethics/Code-of-Ethics/Code-ofEthics-English

Ortman, J. M., Velkoff, V. A., \& Hogan, H. (2014). An aging nation: The older population in the United States, current population reports. United States Census Bureau. https://www.census.gov/library/publications/2014/demo/p25-1140.html

Palmore, E. (1977). Facts on Aging: A short quiz. The Gerontologist, 17(4), 315-320. https://doi.org/10.1093/geront/17.4.315

Spitzer, W. J., \& Davidson, K. W. (2013). Future trends in health and health care: Implications for social work practice in an aging society. Social Work in Health Care, 52(10), 959-986. https://doi.org/10.1080/00981389.2013.834028

Stringer, E., \& Dwyer, R. (2005). Action research in human services. Pearson Education.

United States Bureau of Labor Statistics. (2019). Occupational outlook handbook: Healthcare occupations. United States Bureau of Labor Statistics.

United States Centers for Medicare \& Medicaid Services. (2021). Skilled nursing facility (SNF) care. https://www.medicare.gov/coverage/skilled-nursing-facility-snfcare

Wang, D., \& Chonody, J. (2013). Social workers' attitudes toward older adults: A review of the literature. Journal of Social Work Education, 49(1), 150-172. https://doi.org/10.1080/10437797.2013.755104

Wang, D., Ihara, E., Chonody, J., \& Krase, K. (2013). Social work faculty interest in aging: Impact on education, knowledge, comfort and experience. Gerontology $\mathcal{E}$ Geriatrics Education, 34(3), 257-271.

https://doi.org/10.1080/02701960.2012.718010

World Health Organization. (2018). Ageing and health. http://www.who.int/en/newsroom/fact-sheets/detail/ageing-and-health

Yusoff, M. S., Alias, A. K., \& Salleh, F. (2013). Scholarship of teaching and learning in higher education: An assessment framework. Education in Medicine Journal, 5(2), 1-5. doi: 10.5959/eimj.v5i2.42 
Misty G. Smith, DSW, LMSW-IPR, is an Assistant Professor in Social Work at Tarleton State University where she has taught both undergraduate and graduate courses for ten years. Previously, she has served in administrative roles as the Title IV-E Project Director and Field Education Director preparing students for the integration of theory into practice within social work agency settings. Dr. Smith also serves as a Civic Engagement and Service Learning (CESL) Faculty Fellow for the institution providing faculty mentorship to cultivate faculty interest in the use of CESL within a variety of disciplines across the university.

"SoTL's challenge and its promise, then, are one: a reconceptualization of relationships between the disciplines, and a widening of the scholarly 'trading zone'" (p. 1).

Raffoul, J., Potter, M. K., \& Andrews, D. M. (2021). The SoTL body: Identifying and navigating points of entry. International Journal for the Scholarship of Teaching and Learning, 15(1), Article 5. https://doi.org/10.20429/ijsotl.2021.150105 